\title{
Effect of Percutaneous Coronary Intervention on Blood Pressure in Patients with Hypertension and Coronary Heart Disease in Zagazig University Hospitals
}

\author{
Mahmoud Hassan Shah I, Tamer Mohamed Moustafa I, Ahmed Said El-damanhory I, Fouzi Salim \\ Ahmed Amsheeri ${ }^{\text {II* }}$ \\ ${ }^{I}$ Department of Cardiovascular medicine Faculty of Medicine - Zagazig University, Egypt.

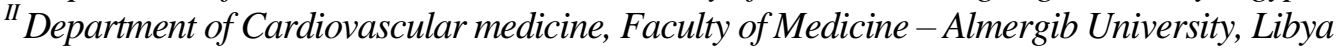

\section{Corresponding Author:}

Fouzi Salim Ahmed

Amsheeri

Department

Cardiovascular

Faculty of

Almergib University, Libya.

Emshairy@gmail.com

Submit Date: 26-04-2019

Revise Date: $15-06-2019$

Accept Date: 22-06-2019

\section{ABSTRACT}

Background: Coronary artery disease (CAD) is a major cause of morbidity and mortality over the world. The atherosclerosis can of developed through many years and symptoms occur, generally in medicine, middle age. The risk of developing CAD increases with age including age $>45$ years in men and $>55$ years in women. Objectives: The presented study was aimed to evaluate the dynamic changes of systolic and diastolic blood pressure in hypertensive patients with ischemic heart disease pre and post percutaneous coronary intervention (PCI), and to determine the effects of PCI on the elevated blood pressure on the CAD patients. Methods: Our study had been carried out in cardiology department, Zagazig University from October 2017 to September 2018. This study included 100 patients with hypertension and coronary artery disease. The patients were subjected for complete history taking, clinical examination, elective PCI and ambulatory blood pressure monitoring before and one month after PCI. Results: Results showed a highly significant difference between the ambulatory blood pressure pre and after coronary intervention, a significant decrease in the mean values of SBP and DBP $(140 / 84 \mathrm{~mm} \mathrm{Hg})$ and the percentage of changes in BP after PCI revealed more decrease at night in the mean values of SBP and DBP compared with percentage at day. Conclusions: PCI is efficiently control and improve the blood pressure among hypertensive patients with CAD.

Keywords: Percutaneous Coronary Intervention, Blood Pressure, Coronary Heart Disease

\section{INTRODUCTION}

$\mathrm{H}$ ypertension is a cardiovascular disease characterized by increas of arterial blood pressure levels [1], it is an important risk factor for cardiovascular disease [2].

Controlling the blood pressure is very important for prevention of heart disease. Practically, the control of blood pressure will be easier after revascularization for patients of hypertension and coronary artery disease.

Many factors can affect blood pressure, including peripheral vascular resistance, blood volume, cardiac output, and the functional status of the target organ and the autonomic function [3]. [4] 
In this study, we explore the effects of percutaneous coronary intervention (PCI) on the ambulatory blood pressure (ABP) of patients with hypertension and coronary artery disease by observing the dynamic characteristics and change trends of $\mathrm{ABP}$ before and after PCI.

The heart can controlled by parasympathetic and sympathetic nerves which maintain the stability and the balance of cardiac activities. The vagus nerve maintains a certain tension and predominates the sympathetic nerve [5]

In coronary heart disease, myocardial ischemia and hypoxia due to coronary artery obstruction stimulate the mechanoreceptor and chemoreceptor on the ventricular wall, increase sympathetic nerve activity and decrease parasympathetic activity. These effects the regulatory function of the autonomic nerve and decrease HRV. The relation between coronary revascularization and HRV has been studied with the relation between arterial blood pressure and HRV[6-8].

Coronary intervention is a nonsurgical procedure used for treating stenosis of the coronary arteries of the heart found in coronary artery disease patients, the procedure uses coronary catheterization to visualize the blood vessels on X-ray imaging After accessing the blood stream through the femoral or radial artery, then the interventional cardiologist can perform a coronary angioplasty, by a deflated balloon into the obstructed artery and inflated to relieve the narrowing; some devices as stents to keep the blood vessel open. The appropriate use of PCI depends on many factors, PCI may be adequate for patients with stable coronary artery disease with certain criteria, such as coronary stenosis greater than $70 \%$ therapy. Although PCI may not prevent death or myocardial infarction over medication for those patients, but it provides better relief of angina [9-10].

In patients with severe coronary artery disease, as ST-segment elevation myocardial infarction (STEMI); PCI can be decrease deaths, myocardial infarctions and angina in comparing two medication [11]. Treatment by medication and/or PCI for patients with nonST-segment elevation myocardial infarction (NSTEMI) or unstable angina depends on a patient's risk assessment [12].

\section{METHODS}

This follow-up study included one hundred patients with hypertension and coronary heart disease who were admitted to cath lab for elective PCI at Cadiology Department, Faculty of Medicine, Zagazig University during the peroid from October 2017 to September 2018. Patients were subjected to full history taking, clinical examination, ECG, laboratory work-up, echocardiography and coronary angiography. All patients diagnosed clearly with Coronary Artery Disease (CAD) according to ACC/AHA guidelines. The patients with $\mathrm{CAD}$ were divided according to their sex into males $(n=62)$ and females $(n=38)$. The patients were subdivided according to the risk factors including diabetes mellitus, and smoking. Moreover, all the studied selected patients have hypertension.

Written informed consent was obtained from all patients and the study was approved by the research ethical committee of Faculty of Medicine, Zagazig University. The work has been carried out in accordance with The Code of Ethics of the World Medical Association (Declaration of Helsinki) for studies involving human

The blood pressure was monitored for whole day, every thirty minutes at the day and every 60 minutes at the night. PCI was performed according to the PCI guidelines. The observed parameters for ABPM included measurement of 24 hour mean Systolic Blood Pressure (SBP), 24 hour mean Diastolic Blood Pressure (DBP), and mean day Systolic Blood Pressure (dSBP), mean day Diastolic Blood Pressure (dDBP), mean night Systolic Blood Pressure (nSBP), mean night Diastolic Blood Pressure (nDBP), ABP Variability (BPV) and blood pressure circadian rhythm.

\section{Statistical Analysis}


Data were collected, tabulated and analyzed by SPSS 20, software for Windows. The significance level was set at $\mathrm{P}<0.05$.

\section{RESULTS}

Table (1) showed that the studied group has a mean age of $57.32 \pm 7.45$ years old, with a range from 38 to 71 years old. About $2 / 3$ of the studied group are male $(62.0 \%)$, and $38.0 \%$ are female., Table (2) showed that the mean age of the studied male patients is $56.81 \pm 8.36$ years old, with a range from 38 to 71years old and mean age of the studied female patients is 58.16 \pm 5.59 years old, with a range from 49 to 71 years old, with no statistically significant difference. Table (3) showed that about half of the studied hypertensive patients are diabetics (43\%), and $52 \%$ of them are smokers. Table (4) showed that $69 \%$ of patients have one vessel disease, $31 \%$ have two vessel disease and $4 \%$ have three vessel diseases. Also showed that $62 \%$ of the studied patients have LAD and $38 \%$ have LCX, RCA is found in $24 \%$ and only $7 \%$ of them have OM. Table (5) showed that the mean of $24 \mathrm{~h}$ SBP among the studied patients before Percutaneous coronary intervention decreased from $(155.81 \pm 17.9 \mathrm{mmHg})$ at the first assessment to $(143.08 \pm 18.86 \mathrm{mmHg})$ at second assessment after Percutaneous coronary intervention with high statistically significant difference. Also there is high significant decrease in $24 \mathrm{~h}$ DBP, mean day SBP and DBP, mean night SBP and DBP. Table (6) showed that mean Percentage of decrease in day SBP among the studied group is $-8.27 \pm 5.47$ with a range from (-21.3-3.45) and mean Percentage of decrease Mean day DBP is $-6.27 \pm 5.94$ with a range from (-22.22-3.33), mean Percentage of decrease in night SBP among the studied group is -8.19 \pm 5.8 with a range from (-20.39-0.57). The mean Percent of decrease in $24 \mathrm{~h}$ SBP among the studied group was $8.19 \pm 5.14$, with a range from (-20-1.13). The mean Percent of decrease in $24 \mathrm{~h}$ DBP was $7.86 \pm 4.79$, with a range from (-20-5). Figure (1) showed that the mean Percent of decrease in $24 \mathrm{~h} \mathrm{SBP}$ among the studied group is $8.19 \pm 5.14$, with a range from ((-20-1.13). A mean Percent of decrease in $24 \mathrm{~h}$ DBP was $7.86 \pm 4.79$, with a range from (-20-5). Figure (2) showed the dipping of blood pressure after Percutaneous coronary intervention in relation to number of affected blood vessels among the studied patients $(\mathrm{N}=100)$.

Table 1. Demographic data of the studied patients:

\begin{tabular}{|c|c|c|}
\hline \multirow[t]{2}{*}{ Demographic data } & \multicolumn{2}{|c|}{ Studied patients $(\mathrm{N}=\mathbf{1 0 0})$} \\
\hline & No. & $\%$ \\
\hline \multicolumn{3}{|l|}{ Age (years) } \\
\hline Mean \pm SD & \multicolumn{2}{|c|}{$57.32 \pm 7.45$} \\
\hline Median (Range) & \multicolumn{2}{|c|}{$55(38-71)$} \\
\hline \multicolumn{3}{|l|}{ Sex } \\
\hline Male & 62 & 62.0 \\
\hline Female & 38 & 38.0 \\
\hline
\end{tabular}

Table 2. age of the studied patients according to sex distribution

\begin{tabular}{|l|c|c|c|c|}
\multicolumn{1}{c|}{ Age (years) } & \multicolumn{2}{|c|}{ sex of the studied group (N=100) } & Test \\
\cline { 2 - 4 } & Male (N=62) & Female (N=38) & 1020.00 \\
\hline Mean \pm SD & $56.81 \pm 8.36$ & $58.16 \pm 5.59$ & 0.257 \\
Median (Range) & $55(38-71)$ & $59(49-71)$ & \\
\hline
\end{tabular}

\# Mann-Whitney $U \quad P<0.05$ is significant. 
Table 3. Risk factors among the studied patients $(\mathrm{N}=100)$.

\begin{tabular}{|c|c|c|}
\hline \multirow[t]{2}{*}{ Item } & \multicolumn{2}{|c|}{ Studied patients $(\mathrm{N}=100)$} \\
\hline & No. & $\%$ \\
\hline \multicolumn{3}{|l|}{ DM } \\
\hline Negative & 57 & 57.0 \\
\hline Positive & 43 & 43.0 \\
\hline \multicolumn{3}{|l|}{ Smoking } \\
\hline Negative & 48 & 48.0 \\
\hline Positive & 52 & 52.0 \\
\hline
\end{tabular}

Table 4. Site of lesion among the studied patients $(\mathrm{N}=100)$.

\begin{tabular}{|c|c|c|}
\hline \multirow[t]{2}{*}{ Item } & \multicolumn{2}{|c|}{ Studied patients ( $\mathrm{N}=\mathbf{1 0 0})$} \\
\hline & No. & $\%$ \\
\hline Single vessel disease & 65 & 65.0 \\
\hline Two vessel disease & 31 & 31.0 \\
\hline Three vessel disease & 4 & 4.0 \\
\hline LAD & 62 & 62.0 \\
\hline LCX & 38 & 38.0 \\
\hline RCA & 24 & 24.0 \\
\hline OM & 7 & 7.0 \\
\hline
\end{tabular}

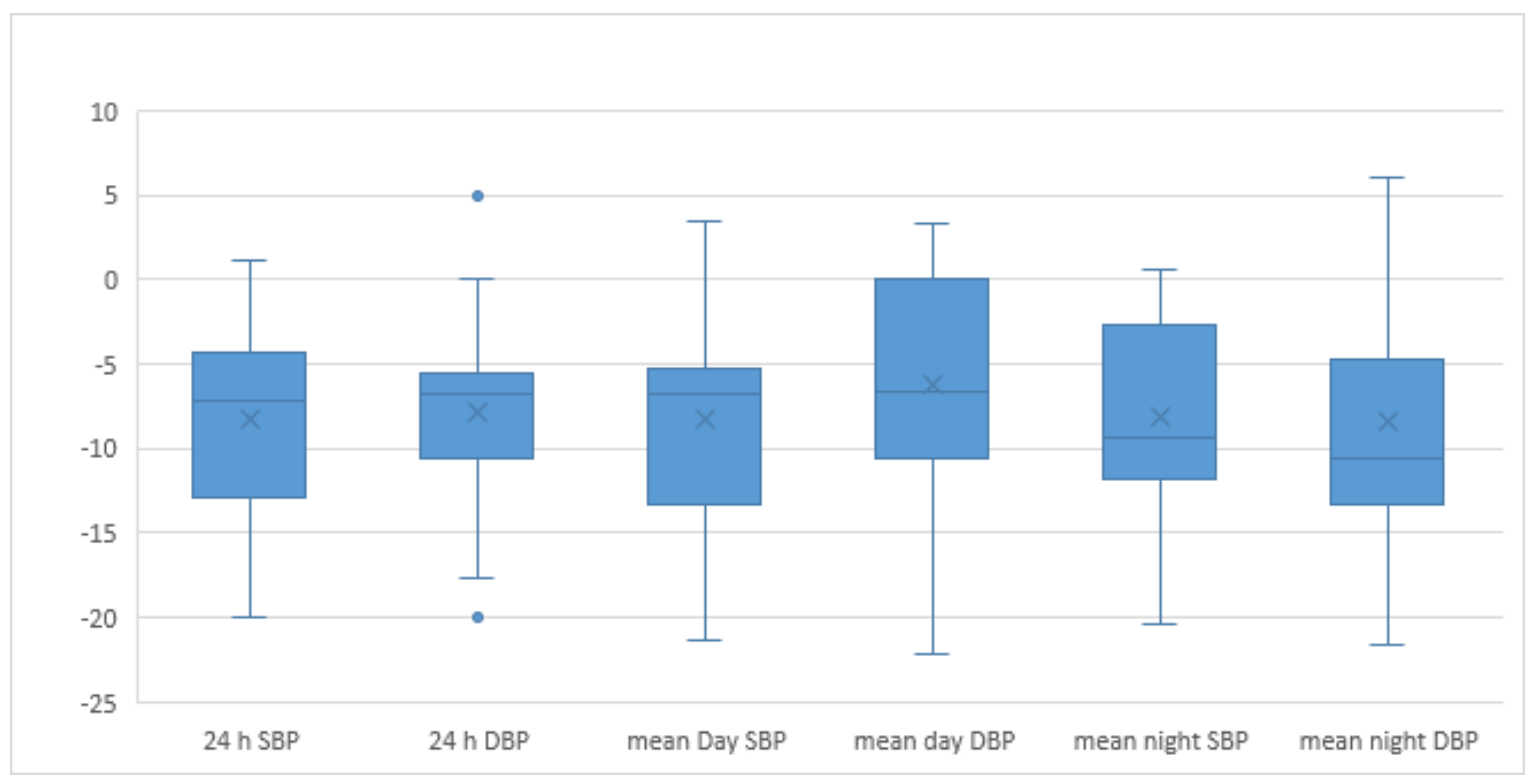

Figure 1. Box plot representing percentage of change in blood pressure before and after percutaneous coronary intervention among the studied patients: 


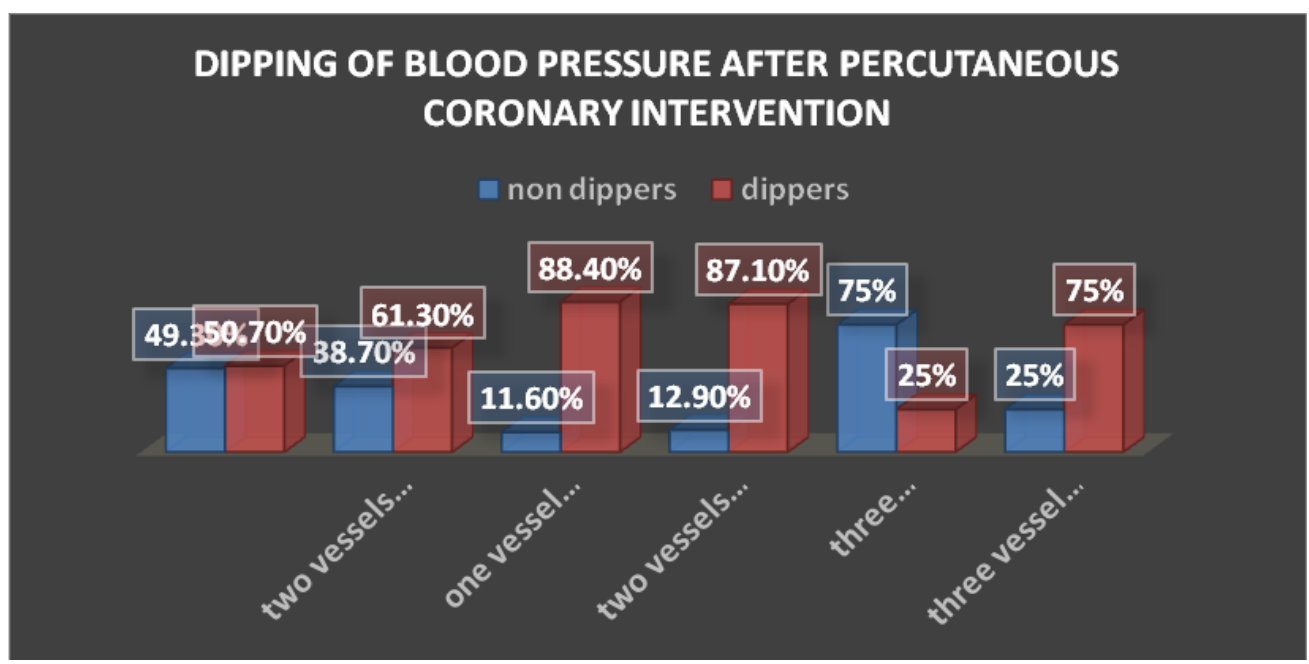

Figure 2. Dipping of blood pressure after Percutaneous coronary intervention in relation to number of affected blood vessels among the studied patients $(\mathrm{N}=100)$.

\section{DISCUSSION}

Hypertension is a cardiovascular disease characterized by increasing of arterial blood pressure which is considered a risk factor for cardiovascular disease [2, 13].

Excessive BP reductions have been advocated as a potential contributor for increasing the risk of coronary events in hypertensive patients under treatment, particularly in those with underlying coronary artery disease [14-15]. Thus, controlling the blood pressure is extremely important to prevent coronary heart disease. In clinical practice, revascularization for hypertension patients can easily control blood pressure [16].

Percutaneous coronary interventions (PCI) have been performed in patients with coronary heart disease and it is the standard optimal treatment for patients with myocardial infarction [17]. However, the impact of hypertensive patients on long-term outcomes of patients after receiving PCI has not yet been determined [18].

The prognostic role of $\mathrm{BP}$ on increased coronary risk, as well as the role of admission $\mathrm{BP}$ on the incidence in recurrent myocardial ischemia after myocardial infarction [19], the hypothesis that BP levels may interfere with the healing process after PCI appears reasonable [20]. The monitoring of ambulatory blood pressure (ABPM) was done to monitor the blood pressure (BP) for detection of white coat hypertension or masked hypertension. BP Variability is associated with increased coronary artery diseases. It is important to recognize the applicability of ABPM in postcoronary intervention. Therefore, the aim of this study was to evaluate the dynamic changes of systolic and diastolic blood pressure in hypertensive patients with ischemic heart disease pre and post percutaneous coronary intervention (PCI), and to determine the effects of PCI on the elevated blood pressure on the CAD patients

Regarding the demographic data of the studied groups, results showed that the mean age was $57.32 \pm 7.45$ years and about $2 / 3$ of the studied group are males (62.0\%), and $38.0 \%$ are females. Similarly, Vasan et al [21] stated that, the hypertension prevalence is directly proportional to the age of the patients; half of Americans > 65 years of age having a hypertension. In a study of Framingham Heart, it was estimated that the remaining lifetime risk of hypertension at $\approx 90 \%$ for men and women not yet hypertensive at middle age, where the change with age in the importance of SBP and DBP as risk factor. In addition, reported that, Mean age was $61.64 \pm 8.50$ years and $(21 \%)$ of the study population were females which may not the accurate reflection of the incidence of 
coronary artery disease (CAD) in women. This may be according to small number of females underwent PCI even now. This was in agreement with study of Yang et al [22] who studied the effect of PCI on ambulatory blood pressure. They reported that, Mean age was $61.18 \pm 12.15$ and most patients were men (76.19\%). The risk factors among the studied patients with coronary artery diseases were smoking and diabetes mellitus in the percentage of $52 \%$ and $43 \%$, respectively. This results was in agreement with study of Lin et al [18] who mentioned that hypertension, diabetes mellitus (DM), dyslipidemia and smoking considered risk factors can also affect CAD patients outcomes whom receiving PCI.

Our result was in disagreement with study of Yang et al [22] who found that, the percentage of DM was $16.67 \%$ and the percentage of smoking was $29.37 \%$. The obtained results of affected coronary artery among the studied patients showed that, most of cases were detected as left anterior descending coronary artery (LAD) in percentage of $62 \%$, left circumflex coronary artery (LCX) in percentage of $38 \%$, right coronary artery (RCA) in percentage of $24 \%$ and obtuse marginal (OM) in percentage of $7 \%$. Our result was in disagreement with Cay [23] who showed that, the most affected coronary artery was right coronary artery (RCA) in percentage $40 \%$, left anterior descending coronary artery (LAD) in percentage of $10 \%$ and left circumflex coronary artery (LCX) in percentage of $8 \%$.

Regarding the blood pressure before and after PCI among the studied patients, our study showed a significant decrease in the mean values of blood pressure (BP) at day, night and whole $24 \mathrm{hr}$ after PCI compared with blood pressure values before applied of PCI for the studied patients $(\mathrm{P}=0.001)$. This results were in agreement with Yang et al [16] showed that, one month after PCI, the ABP significantly improved $(\mathrm{P}<0.01)$.

Our result was in agreement with study of Cay [23] who showed that, the ambulatory BP values including systolic and diastolic $24 \mathrm{~h}$ average, day and night BP were significantly higher in restenosis group compared to no resenosis group.

The cuurent results showed that, before PC intervention $24 \mathrm{~h}$ SBP ranged from $127-$ $190 \mathrm{mmHg}$ and Mean 24h SBP was $155.81 \pm 17.9$ while after PC intervention $24 \mathrm{~h}$ SBP decreased and ranged from 120-180 $\mathrm{mmHg}$, the mean SBP $143.08 \pm 18.86$. Moreover, before PC intervention $24 \mathrm{~h}$ DBP ranged from $80-100 \mathrm{~mm} \mathrm{Hg}$ and mean $24 \mathrm{~h}$ DBP was90.98 \pm 6.01 , while after PC intervention 24 $\mathrm{h}$ DBP decreased and ranged from $70-105 \mathrm{~mm}$ $\mathrm{Hg}$.

These results were in agreement with study of Denardo et al [24] who confirmed that, revascularized patients had lower BP than non-revascularized patients (148.0/83.5 versus 151.9/88.5 mm Hg; for SBP and DBP. As for all of the hypertensive patients, the greatest decrease in BP was seen during the first 6 weeks of treatment, followed by additional decreases during the subsequent 5 months, which were maintained through 24 months.

These results are agreement with the study of Yang et al [16] who reprted that, PCI can decrease myocardial ischemia and relieve angina symptoms and can restore the autonomic function by decreasing sympathetic excitability and increasing parasympathetic excitability. The restore of the blood pressure balance and improving the ambulatory blood pressure parameters, controlling the blood pressure can be more easy after PCI and the study of Denardo et al [24] who suggested that, the comparing of revascularized with nonrevascularized patients increased risk for adverse outcomes, and a higher rate of adverse outcomes despite adequate BP control. Implicating more severe vascular disease, their SBP (but not DBP) was somewhat more difficult to control. Our results represented the percentage of change in blood pressure after PCI in the studied hypertension and coronary heart disease patients which showed decreasing in the mean of SBP and DBP at $24 \mathrm{hr}$. were (7.14 and - 6.7), respectively. This outcomes are be dissimilar with the study of Denardo et al 
[24] who showed that, the relationships between the incidence of primary outcome and mean follow-up SBP and DBP for the revascularized and non revascularized patients showed a lesser degree for SBP and a greater degree for DBP, pulse pressure decreased less for revascularized patients than for nonrevascularized patients (adjusted for baseline BP: -6.5 versus $-9.6 \mathrm{~mm} \mathrm{Hg}$; $\mathrm{P}<0.001)$.

The treating of hypertensive patients with coronary diseases have benefits but the major impact on long-term morbidity and mortality depends on the effect of continued outpatient BP control after starting the effective therapy in hospital [25]. Our study showed that among cases with single affected blood vessel, $50.7 \%$ of the studied patients have nocturnal fall of diastolic pressure more than 10\% (dippers) before Percutaneous coronary intervention, while after Percutaneous coronary intervention percentage of dippers increased to be $88.4 \%$ with high statistically significant difference.

There is high significant increase of dipping in patients with two blood vessels affected but there is no significant change of dipping among patients with three blood vessels affected. Rechcin'ski et al [26] conducted that, recurrent angina pectoris resulted from inability of fluctuations adjustment in blood pressure which leads to continuously nighttime blood pressure increase; so; the mean blood pressure and blood pressure variability increase, then the circadian rhythm decreases or disappears. This hypothesis was confirmed by study of Yang et al [16] who demonstrated that, the blood pressure balance was not restored at 3-6 days after PCI. However, 1 month after PCI, the reduced myocardial ischemia and the blood pressure balance was restored.

\section{CONCLUSION}

PCI is efficiently control and improve the blood pressure among hypertensive patients with CAD.

\section{Declaration of interest}

The authors report no conflicts of interest. The authors alone are responsible for the content and writing of the paper.

Funding information None declared

\section{REFERENCES}

1. Messerli FH and Panjrath GS. The J-curve between blood pressure and coronary artery disease or essential hypertension: exactly how essential?. J Am Coll Cardiol. 2009; 54: 182734.

2. Cahan A, Ben-Dov IZ and Bursztyn $M$. Association of heart rate with blood pressure variability: implications for blood pressure measurement. Am J Hypertens. 2012; 25: 313318.

3. Wang J, Khoury DS, Yue Y, Torre-Amione $G$ and Nagueh SF. Preserved left ventricular twist and circumferential deformation, but depressed longitudinal and radial deformation in patients with diastolic heart failure. Eur Heart J. 2008; 29: 1283-1289.

4. Fagard RH, Pardaens $\mathbf{K}$ and Staessen JA. Relationships of heart rate and heart rate variability with conventional and ambulatory blood pressure in the population. J Hypertens. 2001; 19: 389-397.

5. Habibzadeh MR, Farzaneh-Far $\mathbf{R}$ and Sarna P. Association of blood pressure and heart rate response during exercise with cardiovascular events in the Heart and Soul Study. J Hypertens. 2010; 28: 2236-2242.

6. Kunz VC, Souza RB and Takahashi AC. The relationship between cardiac autonomic function and clinical and angiographic characteristics in patients with coronary artery disease. Rev Bras Fisioter. 2011; 15: 503-510.

7. Hallas CN, Thornton EW, Fabri BM, Fox MA and Jackson M. Predicting blood pressure reactivity and heart rate variability from mood state following coronary artery bypass surgery. Int J Psychophysiol. 2003; 47:43-55

8. Cabezas-Cerrato J, Hermida RC, CabezasAgricola JM and Ayala DE. Cardiac autonomic neuropathy, estimated cardiovascular risk, and circadian blood pressure pattern in diabetes mellitus. Chronobiol Int. 2009; 26: 942-957

9. Pursnani S, Korley F, Gopaul R, Kanade P, Chandra N, Shaw RE, et al. Percutaneous coronary intervention versus optimal medical therapy in stable coronary artery disease: a systematic review and meta-analysis of randomized clinical trials. Circ Cardiovasc Interv. 2012; 5 (4): 476-490.

10. O'Gara PT, Kushner FG, Ascheim DD, Casey DE, Chung MK, de Lemos JA, et al. 2013 ACCF/AHA guideline for the management of 
ST-elevation myocardial infarction: a report of the American College of Cardiology Foundation/ American Heart Association Task Force on Practice Guidelines. Circulation. 2013; 127 (4): e362-425.

11. Stauber BD, Venugopal $\mathbf{S}$ and Amsterdam EA. Treading lightly: ST-segment elevation on an exercise electrocardiogram. Am J Med. 2016; 123-127.

12. Gorenoi V and Hagen A. Percutaneous coronary intervention in addition to optimal medical therapy for stabile coronary artery disease - a systematic review and metaanalysis. Deutsche medizinische Wochenschrift (1946). 2014; 139 (20): 1039-1045.

13. Messerli FH and Panjrath GS. The J- curve between blood pressure and coronary artery disease or essential hypertension: exactly how? J Am Coll Cardiol. 2009; 54: 1827-1834.

14. Haller H, Ito S, Izzo JL, Januszewicz A, Katayama S, Menne J, et al. Olmesartan for the delay or prevention of microalbuminuria in type 2 diabetes. N Engl J Med. 2011; 364 : 907-917.

15. Parving HH, Brenner BM, McMurray JJ, de Zeeuw D, Haffner SM, Solomon SD, et al. Cardio renal end points in a trial of aliskiren for type 2 diabetes. N Engl J Med. 2012; 367: 2204-2213.

16. Yang J, Yang X, Liu W and Cao T. Effects of percutaneous coronary intervention on the ambulatory blood pressure of patients with hypertension and coronary heart disease. Irish Journal of Medical Science (1971 -). 2015; 184(4): 845-850.

17. Wijns W, Kolh P, Danchin N, Di Mario C, Falk V, Folliguet $\mathbf{T}$, et al. Guidelines on myocardial revascularization. Eur Heart $\mathrm{J}$. 2010; 31: 2501-2555.

18. Lin M, Chen C, Lin $\mathbf{H}$ and Wu H. Impact of diabetes and hypertension on cardiovascular outcomes in patients with coronary artery disease receiving percutaneous coronary intervention. BMC Cardiovascular. 2017; 17: 12.
19. Roth D, Van Tulder R, Heidinger B, Herkner H, Schreiber $W$ and Havel C. Admission blood pressure and 1-year mortality in acute myocardial infarction. Int J Clin Pract. 2015; 69(8): 812-819.

20. Tocci G, Barbato E, Coluccia P, Modestino A and Pagliaro B. Blood Pressure Levels at the Time of Percutaneous Coronary Revascularization and Risk of Coronary InStent Restenosis. American Journal of Hypertension 2016; 29(4).

21. Vasan RS, Beiser A, Seshadri S, Larson MG, Kannel WB, D'Agostino RB, et al. Residual lifetime risk for developing hypertension in middle-aged women and men: the Framingham Heart Study. JAMA. 2002; 287: 1003-1010.

22. Yang JW, Wang YT and Lu CZ. Coronary arteriography in the diagnosis results and prognosis analysis of suspected coronary artery disease in patients with normal SPET myocardial perfusion imaging. Hell $\mathrm{J}$ Nucl Med 2015; 18(3): 215-221.

23. Cay S. Forgotten indices of ambulatory blood pressure profile. Int J Cardiol. 2011; 147 (3): 45.

24. Denardo S, Gaxiola E, ArandaJr J, Cooper-DeHoff R, Handberg $E$ and Gong Y. Characteristics and Outcomes of Revascularized Patients With Hypertension. Hypertension. 2009; 53: 624-630.

25. Rosendorff C, Lackland DT, Allison M, Aronow WS, Black HR, Blumenthal RS, et al. Treatment of hypertension in patients with coronary artery disease: A scientific statement from the American Heart Association, American College of Cardiology, and American Society of Hypertension. J Am Soc Hypertens. 2015; 9 (6): 453-498.

26. Rechcin'ski T, Trzos E and WierzbowskaDrabik K. Melatonin for nondippers with coronary artery disease: assessment of blood pressure profile and heart rate variability. Hypertens Res. 2010; 33: 56-61.

To cite this article:Shah MH, Moustafa TM, El-damanhory AS, Amsheeri FSA. Effect of Percutaneous Coronary Intervention on Blood Pressure in Patients with Hypertension and Coronary Heart Disease in Zagazig University Hospitals. Zumj May. 2020(26) No.3,434-441.Doi. 10.21608/zumj.2019.11323.1203. 